\title{
The Role of Physical Appearance in the Peer Acceptance of Emerging Adults Undergoing Chemotherapy
}

\author{
Megan E. Samples \\ West Virginia University
}

Follow this and additional works at: https://researchrepository.wvu.edu/etd

\section{Recommended Citation}

Samples, Megan E., "The Role of Physical Appearance in the Peer Acceptance of Emerging Adults Undergoing Chemotherapy" (2014). Graduate Theses, Dissertations, and Problem Reports. 464. https://researchrepository.wvu.edu/etd/464

This Thesis is protected by copyright and/or related rights. It has been brought to you by the The Research Repository @ WVU with permission from the rights-holder(s). You are free to use this Thesis in any way that is permitted by the copyright and related rights legislation that applies to your use. For other uses you must obtain permission from the rights-holder(s) directly, unless additional rights are indicated by a Creative Commons license in the record and/ or on the work itself. This Thesis has been accepted for inclusion in WVU Graduate Theses, Dissertations, and Problem Reports collection by an authorized administrator of The Research Repository @ WVU. For more information, please contact researchrepository@mail.wvu.edu. 
The Role of Physical Appearance in the Peer Acceptance of Emerging Adults Undergoing Chemotherapy

Megan E. Samples

Thesis submitted to the College of Education and Human Services at West Virginia University

in partial fulfillment of the requirements for the degree of

Master of Arts

in

Educational Psychology

with an emphasis in Child Development and Family Studies

Jessica Troilo, Ph. D., Committee Chairperson

Amy Root, Ph. D., Committee Member

Laurie Theeke, Ph. D., Committee Member

Department of Learning, Sciences, and Human Development

Morgantown, West Virginia

2014

Keywords: peer acceptance, physical appearance, cancer, emerging adults

(C) 2014 Megan E. Samples 


\section{Abstract \\ The ROLE OF PHYSICAL APPEARANCE IN THE PEER ACCEPTANCE OF EMERGING ADULTS UNDERGOING CHEMOTHERAPY}

\section{by Megan E. Samples}

Peer acceptance has been shown to influence the overall social development of an individual and physical appearance has been shown to be heavily influential in the overall peer acceptance of an individual. This study considered how appearing as if undergoing treatment for cancer impacted peer acceptance. A sample of 182 emerging adults (79\% female; $21 \%$ male) evaluated four types of hypothetical emerging adult peers (a healthy male, a healthy female, a male who appears to be undergoing chemotherapy, and a female who appears to be undergoing chemotherapy. Results showed that the healthy female model had significantly higher peer acceptance scores compared to the healthy and chemotherapy male models. A positive association between microsystem exposure to cancer and peer acceptance ratings was also found. Clinical applications to foster more microsystem influences and future directions, such as use of video vignettes, are provided. 


\section{Dedication}

For my parents, Kevin and Lisa Samples 


\section{Acknowledgements}

I would like to thank the members of my committee: Dr. Jessica Troilo, Dr. Amy Root, and Dr. Laurie Theeke. I am most grateful in your willingness to share your knowledge and time with me. The guidance you all have provided has made me a better student and researcher.

To my advisor, Jessica Troilo, thank you! You were a large reason as to why I came to WVU and it has been a wonderful two years. I am deeply grateful for your encouragement and guidance, academically, professionally, and personally. You have pushed me to be a better student, instructor, and person.

Thank you to the individuals who helped to create my vignettes. Erika Fletcher, you were a wonderful model. Steven Diller, thank you for the countless hours it took to alter the photos. Without you all, my project would not have been possible.

Lastly, I want to thank my family for their support and encouragement in my academic studies, as well as my personal and professional pursuits. To my parents, you have instilled in me a love for school and research. Without either of you, the completion of this thesis and Master's degree would not have been possible. To Colleen, thank you for believing in me. You always know what to say. To Geoffrey, you were the best male model for this thesis. You will never understand what that means to me. 


\section{Table of Contents}

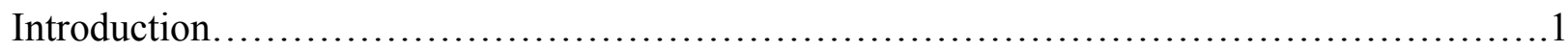

Justification of Study ...................................................

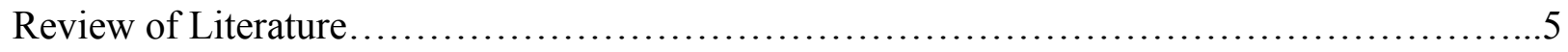

Emerging Adulthood.......................................................5

Influences on Peer Relationships..........................................

Physical Appearance and Peer Acceptance.................................

Chronic Illness and Peer Relationships................................9

The Current Project.........................................................11

Theoretical Framework....................................................... 13

Microsystem...........................................................14

Influence of Peers..................................................... 15

Chronosystem................................................................ 17

Cancer as a Chronic Illness............................................ 17

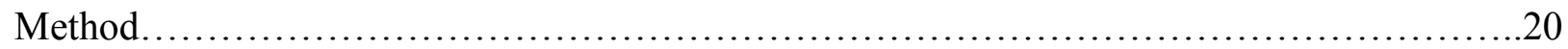

Participants............................................................. 20

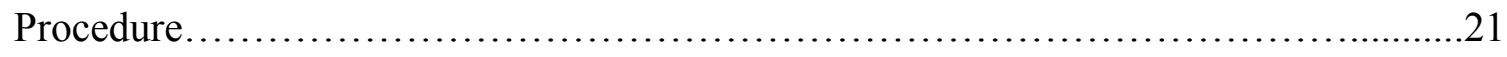

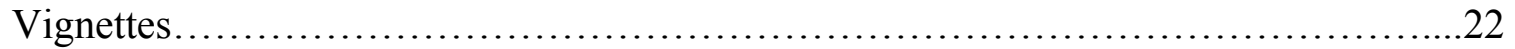

Peer Acceptance Measure.....................................................24

Data Analysis............................................................25

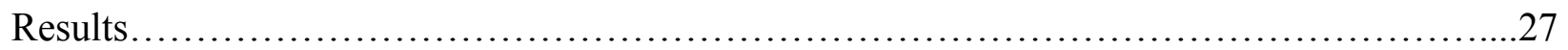

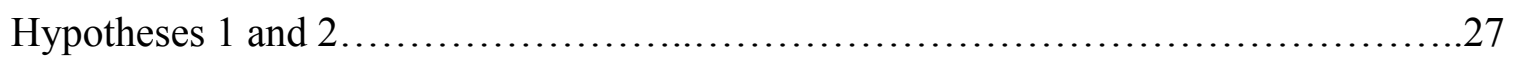

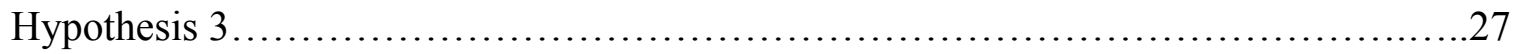




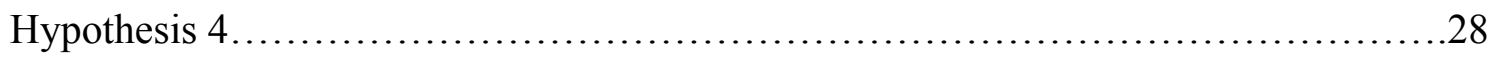

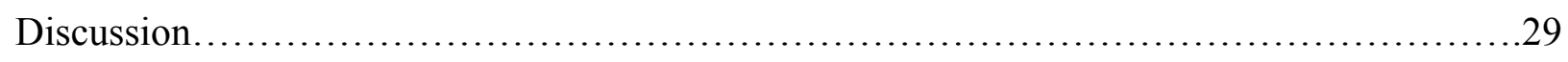

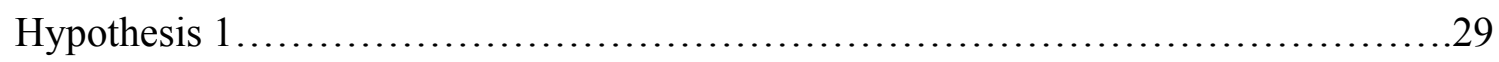

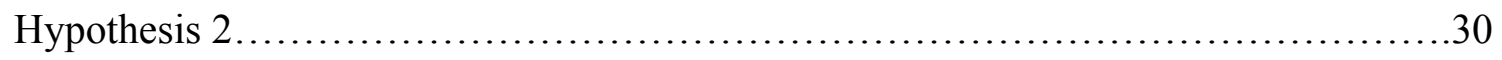

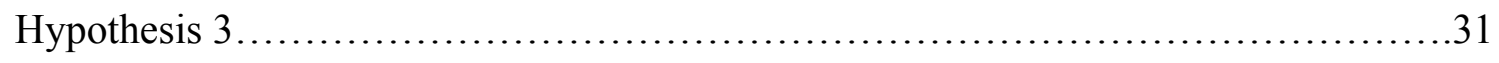

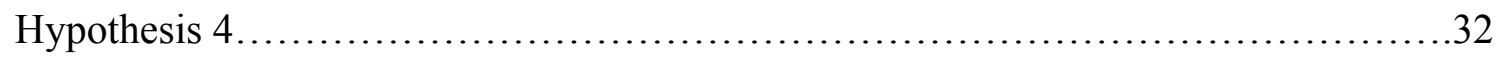

Limitations and Future Directions......................................... 32

Gender Bias..................................................... 33

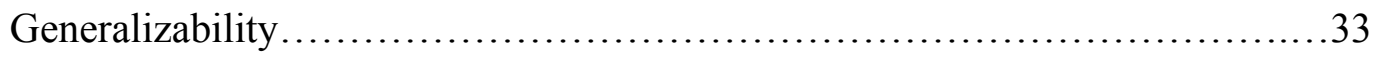

Mixed-methods Study.............................................33

Utilization of Video Vignettes.......................................... 34

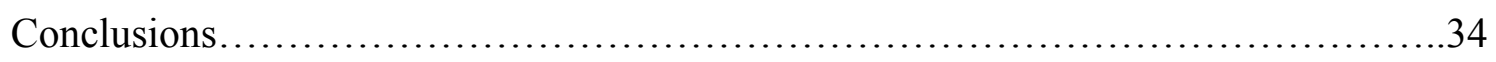

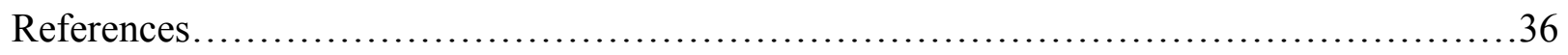




\section{List of Appendices}

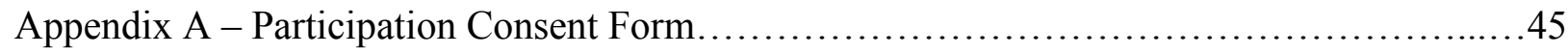

Appendix B - Demographic Questionnaire .......................................46

Appendix C - Healthy Male Vignette.............................................47

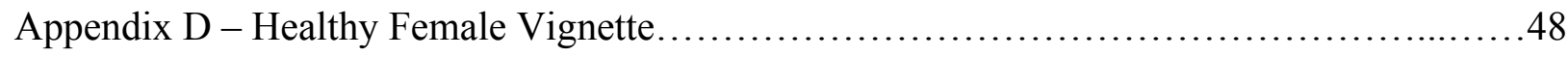

Appendix E - Chemotherapy Male Vignette......................................49

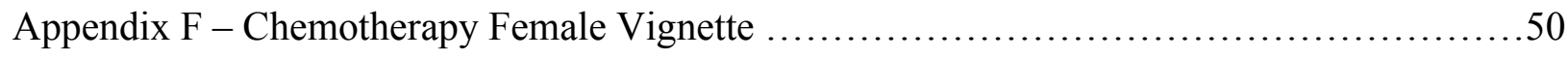

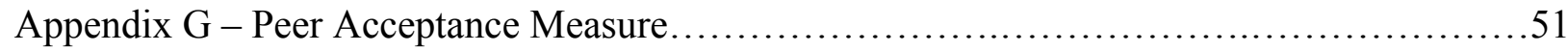




\section{Chapter I}

\section{Introduction}

The extent to which an individual is accepted or rejected by a peer or peer group is known as peer acceptance (Oberle, Schonert-Reichel, \& Thomson, 2010). The degree of peer acceptance is influential to an individual's social and emotional adjustment (Bagwell, Newcomb, \& Bukowski, 1998; Kingery, Erdley, \& Marshall, 2011). Parker and Asher (1993) found that elementary school aged children who were more accepted by their peers were more likely to have a best friend. Furthermore, adolescents' peer acceptance has been found to be positively associated with mutual friendships (Badaly, Schwartz, \& Gorman, 2012; Woodhouse, Dykas, \& Cassidy, 2012). Lack of peer acceptance results in feelings of loneliness (Kingery et al., 2011; Woodhouse et al., 2012) and lowered self-esteem (Kingery et al., 2011) as a result of internal conflict to meet basic human needs in the childhood and adolescent years (Newsom et al., in press).

Specific factors that influence individual peer acceptance or rejection have been identified. Factors that have been positively associated with peer acceptance have included secure parent-child attachments (Dykas et al., 2008), positive emotional states of the individual (Perry-Parrish \& Zeman, 2011; Woodhouse et al., 2012), pro-social behaviors (Oberle et al., 2010; Smith, Rose, \& Scwartz-Mette, 2010; Zakin, 1983), and physical attractiveness (Lyu \& Gill, 2012; Vannatta et al., 2009; Zakin, 1983) were influencing factors positively associated to peer acceptance. Furthermore, Zakin (1983) compared the physical attractiveness, sociability, and athletic competence of individuals and how this affects peer acceptance. He reported that children preferred physically attractive peers to sociable or athletically competent peers, suggesting that children prefer looks to personality and accomplishments. Though these factors 
have been examined in samples of children, there is still a lack of research on the influencing factors of peer acceptance for populations in the developmental phase of emerging adulthood, a period in which peers become more a direct influence (Arnett, 2000; Pascarella \& Terenizini, 1991).

Emerging adulthood is conceptualized as the developmental period between adolescence and young adulthood, including the ages of 18-25 years (Arnett, 2000). During this developmental period, individuals live in numerous types of living situations and they are more likely to be pursuing a college degree (undergraduate or graduate). Arnett (2000) uses the word "instability" to describe this period due to the inconsistency of school and living situations because of college attendance and the numerous transitions (e.g., high school to college, college to a professional job). This description of instability, or change, would suggest that an individual is continuously exposed to new social scenarios and peers.

In adolescence, individuals are immersed in a culture that is heavily influenced by their family and peers, but during the college years, parents are relied on less and their peers more (Arnett, 2000; Pascarella \& Terenizini, 1991). In addition, Pascarella and Terenizini (1991) found that college students were more open to diversity, indicating a growing maturity and potentially wider acceptance of peers. This would suggest that individuals in emerging adulthood have a higher likelihood of accepting peers who are different compared to adolescents and younger developmental ages. Looking at studies of adolescents diagnosed with a chronic illness, they are more likely to have fewer friends (Deasy-Spinetta, 1993; Enskar, Carlsson, Golsater, Hamrin, 1997; Kashikar-Zuck et al., 2007) than their healthier peers. It is not known, however, whether or not emerging adults who are currently undergoing treatments for a serious illness, 
such as cancer, are accepted by their peers, because of their growing maturity level compared to adolescence.

More than 60,000 individuals between the ages of 15 and 39 are diagnosed with cancer each year (National Cancer Institute, 2012a). Most undergo medical treatments (such as radiation, surgery, and chemotherapy) and therefore, are at increased risk for experiencing possible accompanying side effects that can change physical appearance (e.g. hair loss).

Contradictory findings have been reported from studies of how individuals with visible medical conditions, such as cancer, are viewed by their peers. Gray and Rodrigue (2001) reported that middle school students are more accepting of peers who appear to have cancer. On the contrary, King, MacDonald, and Chambers (2010) found that children with observable medical conditions were less socially accepted by peers compared to healthy counterparts. Furthermore, Pendley, Dahlquist, and Dreyer (1997) reported that adolescent cancer survivors engaged in fewer than half of the number of social interactions as the healthy comparison group. Therefore, it is the aim of this study to describe and compare the peer perceptions of emerging adults' based on two groups: peers who appear to be undergoing chemotherapy treatments for cancer and peers who do not.

\section{Justification for the Study}

Though emerging adulthood has been shown to be a distinct period from adolescence and young adulthood, few studies have specifically examined this age group. Even fewer studies have assessed peer relationships of emerging adults despite finding that peers become more of a direct influence than their parents (Arnett, 2000; Pascarella \& Terenizini, 1991). Previous research on peer relationships suggests that individuals who are accepted by their peers have a lower likelihood of dropping out of school (Parker \& Asher, 1987) and better later social 
adjustment (Bagwell et al., 1998; Kingery et al., 2011). By accurately describing the peer acceptance of emerging adults who look as if they are undergoing chemotherapy, critical knowledge will be acquired that has the potential to lead to innovative intervention developmental aimed to enhance peer acceptance in this population. Enhanced peer acceptance could lead to diminished psychological distress, loneliness, and drop-out rates for those with cancer; all of which could have long-term effects on the life course of an emerging adult.

Physical appearance is a significant determining factor of peer acceptance and physically attractive individuals tend to have higher peer acceptance rates than those not perceived as physically attractive (Iobst et al., 2009; Lansu \& Cillessen, 2012; Vannatta et al., 2009; Zakin, 1983). Individuals who have cancer often experience hair loss, sunken eyes, weight loss, pallor, fatigue, and other physical symptoms related to chemotherapy treatments. Because peer acceptance has been found to be an important influence on the individual, understanding how emerging adults think about hypothetical peers who appear to be undergoing chemotherapy is an important first step in learning how emerging adults with cancer may be perceived by their peers. Further, the information learned in this study may be of use to practitioners and hospital staff who work with emerging adults with cancer as they become healthier and re-enter their social worlds. 


\section{Chapter II \\ Review of Literature}

\section{Emerging Adulthood}

Arnett has proposed and supported a distinct developmental period in industrialized nations between adolescence and young adulthood called emerging adulthood, which begins around the age of 18 and ends around 25 (Arnett, 2000; 2002; 2004; 2007; Montgomery, 2005). At the base of his theory, Arnett (2004) posits that there are five distinguishing features that set emerging adulthood apart from adolescence and young adulthood: age of identity exploration (the emerging adult is discovering and testing who they are and are not), age of instability (the emerging adult undergoes various transitions and revisions in the lifestyle), age of self-focus (the emerging adult has few adult responsibilities and commitments), age of feeling in-between (feel as if they are too old to be an adolescent, but too young to be an adult), and the age of possibilities (the future is undecided). For the purpose of this paper, age of identity exploration and age of instability will be discussed, as those two aspects of emerging adulthood will be the focus of this project.

Identity formation has long been thought of as a process completed in adolescence (Arnett, 2004), yet with changes in society this may no longer be the case. At the beginning of the $20^{\text {th }}$ century, the onset of puberty for boys and girls was around 15 years of age, a time when a majority of teenagers dropped out of school and began to work (Arnett, 2000). In essence, they took on adult responsibilities. The end of adolescence in the early 1900s was marked by marriage, typically the late teens or early twenties, and birth of the first child, which occurred somewhere in a person's early to mid-twenties, and marked the transition to adult responsibilities (Arnett, 2000). Currently, puberty starts about two years earlier (around 13 years old; Arnett, 
2000), and the average ages at which women and men first marry are 25.8 and 28.3 , respectively (Copen, Daniels, Vespa, \& Mosher, 2012). This indicates that, according to previous developmental pathways, adolescence starts earlier, young adulthood starts later and their time of identity exploration lasts longer compared to those from previous generations, regardless if they attend college or go straight into the workforce after high school. In the context of peers and relationships, emerging adults are learning more about themselves and what they desire in another person for the future, compared to adolescents who are more concerned about the here and now (Arnett, 2004).

Young adulthood is associated with work and family responsibilities and stability, whereas emerging adulthood is the lack thereof (Arnett, 2000; 2004). When 18-25 year olds were asked if they felt as if they were adults, around $60 \%$ of the participants responded with no (Arnett, 2004; Hamilton, 1994), which indicated that individuals during this age range do not identify with the young adulthood title that is often attributed to them. After the age of 18 , individuals are faced with a variety of options that were not present before. Go to college or get a job? If college, what major? To live at home, in the dormitories, or in an apartment? These choices are just a small sample of what emerging adults are making, and they are faced with multiple options and decisions each year. Marked by the inconsistency of their lifestyle (e.g. changes in living situations, school transitions, searching for a stable job), emerging adults remain separate from adolescents and young adults.

Despite the lack of stability across school and living situations, peers become one of the constant, direct influences in the lives of emerging adults (Arnett, 2000; Pascarella \& Terenizini, 1991) compared to parents in the preceding years. During emerging adulthood, the child typically moves out of the house and into a new setting, reducing the amount of face-to-face 
contact with the parent (Arnett, 2004). Within this new setting, the emerging adult can live with peers increasing the direct contact with peers compared to adolescence. It should be noted that the drop in parental influence and the influence of peers are voluntary influences based on the self-controlled choices of the emerging adult (Arnett, 2007). Despite the knowledge that emerging adulthood is a separate developmental stage from adolescence and young adulthood, research is lacking in some areas of this stage. For example, researchers are unclear about how emerging adults perceive peers whose physical appearance differs from their own as well as how chronic illness influences peer acceptance among emerging adults. This information would allow medical professionals (e.g., nurses, therapists, etc.) to design and incorporate appropriate forms of social support specifically for emerging adults. Therefore this project seeks to understand how peer acceptance, among a sample of emerging adults, is influenced by the physical effects of suffering from a chronic illness, such as cancer.

\section{Influences on Peer Relationships}

Physical appearance and peer acceptance. Much research has been done on gender differences in physical appearance perceptions and influences. In a study conducted by Davison and McCabe (2006) concerning the relationship between psychosocial functioning and adolescent's own body image, it was found that both males and females who were satisfied with their own bodies and less anxious about others' perceptions of their bodies had higher rates of self-esteem. For girls, however, others' negative evaluations about their physical appearances were positively correlated with low self-worth. The authors observed that these evaluations from others were more influential than the girls' own personal views of their body image.

Seidah and Bouffard (2007) reported similar results with a stronger association between girls' physical appearance satisfaction and their self-esteem compared to boys among seventh, 
ninth, and eleventh graders. Yet, if males based their self-esteem on their physical appearance, the effect sizes become less pronounced, meaning that the relationship between boys' physical appearance satisfaction and their self-esteem becomes more similar to girls. In a study with college students investigating the perceived messages of physical appearance, the authors found that messages suggest men should be lean and muscular and women should be thin (Gillen \& Lefkowitz, 2009). Compared to men, women perceived that the media and their peers mostly communicated this thin body ideal. Furthermore, women were more likely than men to recognize the message that the ideal physical attractiveness leads to success. Therefore, taken together, these studies provide evidence that there are differences in physical appearance perceptions between genders.

Previous research suggests that the perceived physical appearance can influence how a peer group accepts an individual. Zakin (1983) compared three qualities of third and eighth grade children that determine peer acceptance: physical attractiveness, sociability, and athletic ability. Across all comparisons, children consistently favored peers who were physically attractive over those who were athletic or were nice. Furthermore, the perceived physical attractiveness of an individual was found to be the strongest correlate of social outcomes compared to academic competence and athletic ability (Vannatta et al., 2009). In a study conducted on the difference between accepted peers and popular peers in emerging adults, it was found that physical attractiveness was a characteristic of both accepted and popular peers (Lansu \& Cillessen, 2012).

Some studies have looked at specific physical characteristics and the rate of peer acceptance. For example, Iobst et al. (2009) researched the peer acceptance rates of children between the ages of 3 and 11 years old by asking peers to assign descriptive words (e.g. nice, mean) to an overweight model. Their results indicated that children assigned fewer positive 
words to the model if the child blamed the model for being overweight. It was also found that the relationship between age and acceptance was linear. Overall, physical appearance plays a critical role in the perceptions of peers and peer acceptance. Yet current research on specific physical characteristics has only focused on body types. With the rise in cancer diagnoses in the United States and the possible physical side effects of the medical treatments (e.g. baldness), it is critical for research to be conducted in this area.

Chronic illness and peer relationships. Research has shown that upon the diagnosis of a chronic illness (e.g. cancer, cystic fibrosis), individuals are more likely to report changes in their social lives and differences from their healthy counterparts. One study using participants between the ages of 16 months and 25 years who underwent bone marrow transplants found that the adolescents were significantly less likely to engage in social activities than their healthy counterparts (Pitt, Lavery, \& Wager, 2009). According to self, peer, and teacher reports, adolescents with juvenile fibromyalgia syndrome were reported to be more sensitive and isolated compared to their healthy peer counterparts (Kashikar-Zuck et al., 2007). On the other hand, emerging adults diagnosed with juvenile idiopathic arthritis did not differ from their peers in rates of popularity, number of close friends, and social support (Gerhardt et al., 2011), suggesting that different chronic conditions may have varying social impacts or perceptions of peers change from one developmental age group (adolescence) to another (emerging adulthood). Much research has been devoted to studying individuals diagnosed with cancer, and the results are similar to the findings for those with chronic illnesses. Studies show that children and adolescents diagnosed with cancer are more likely to display signs of social withdrawal (Benner \& Marlow, 1991; Glasson, 1995; Pini, Hugh-Jones, \& Gardner, 2012; Roberts, Turney, \& Knowles, 1998; Schultz et al., 2007), meaning that their exposure to peers is diminished, and 
therefore their opportunity to be peer accepted. Furthermore, research has indicated that adolescents with cancer have fewer reciprocated friends (Noll, LeRoy, Bukowski, Rogosch, \& Kulkarni, 1991) compared to healthy individuals. More specifically, when asked to describe their social interactions, adolescents' responses included "disappearing" of friends due to lack of interest and fear of knowing the medical details, decrease in the number of friends, and the inability to socialize as desired (Mattsson, Ringnér, Ljungman, \& von Essen, 2007). In support, Meltzer and Rourke (2005) conducted a study with adolescent cancer survivors at an oncology summer camp and found that participants who reported feeling different than their healthy peers, were lonelier, and more socially isolated compared to survivors who did not believe they were different.

There has been concern that due to the prevalence of these diagnoses and the invasiveness of the medical requirements of the condition, there is a decrease in school engagement for these individuals (Pini et al., 2012). School is the primary environment in which children and adolescents interact with their peers. Children and adolescents with cancer miss approximately 43 days out of a 180-day school year (Lansky, Cairns, \& Zwartjes, 1983; National Center for Education Statistics, 2011), resulting in missing out on critical peer interaction time. These missing days are found to be a great source of stress and concern for adolescents who are re-entering the school system after extended absence. Not only do students feeling overwhelmed in catching up with schoolwork (Glasson, 1995; Mattsson et al., 2007), they report feeling behind emotionally, physically and socially (Glasson, 1995). Reasons for their distress include interacting with old friends and peers (Chekryn, Deegan, \& Reid, 1986; Pini et al., 2012) and an altered physical appearance (Bellizzi et al., 2012; Pini et al., 2012). One study found that $40 \%$ of the participants had been teased about their lack of hair by peers (Wasserman, Thompson, 
Wilimas, \& Fairclough, 1987), suggesting that the combination of having a chronic illness and its effect on physical appearance combine to impact peer acceptance.

Research, however, has not been conducted on emerging adults with cancer and their school absence, possibly for a variety of reasons. After high school, continuing one's education becomes voluntary; therefore, not all emerging adults are enrolled in college (Arnett, 2000). In addition, the academic experience of college can be vastly different from high school. In college, students' schedules vary due to their higher level of control compared to being in school for six hours at a time, five days a week in high school. This suggests that missing classes in college may not hold the same significance as it does for individuals in the public school system. Compared to high school, missing college courses is losing critical time in self-exploration with peers and career interests. Furthermore, if one is absent from class for health concerns, it can be assumed they are missing other activities outside of class that aid in the development of peer relationships (e.g., gym, clubs, restaurants, etc.). However, because this topic has not been studied, the impact of missing college courses and activities on peer relationships of the emerging adult is unknown.

\section{The Current Project}

Upon a chronic illness diagnosis, the direct and indirect impact upon the life of the individual is of the utmost concern to the family members, doctors, teachers (if in school), and the individual. Some chronic illnesses, such as cancer, result in physical changes on the individual, which in turn influences their daily social interactions. It has been found that children view peers who visibly have a medical condition as not as well-liked (King et al., 2010). In contrast, another study, using vignettes to study how adolescents perceived hypothetical students with cancer, contradicted these findings. Gray and Rodrigue (2001) found that the ratings of 
hypothetical students with and without cancer did not differ. Further, participants had more positive behavioral intentions toward the students with cancer. In addition, regardless of the model's healthy status, hypothetical female students were seen more positively than the hypothetical male students. Furthermore, Pendley et al., (1997) reported that there was not a difference in the physical attractiveness ratings between adolescent cancer survivors and their healthy counterparts. These results combined suggest that the knowledge of a person having cancer is not the sole determent for peer acceptance, but it remains unclear how a cancer diagnosis impacts peer relationships among emerging adults.

Researchers have identified a variety of influences that impact peer acceptance, which included, but are not limited to physical appearance and chronic illness. The majority of the researchers who studied physical appearance, however, relied on adolescent samples and focused on the impact of self-esteem (e.g., Davison \& McCabe, 2006), attractiveness (e.g., Zakin, 1983), and weight (e.g., Iobst et al., 2009). Others have studied how having a chronic illness impacts peer relationships. Again, these researchers have focused on young children or adolescent samples and considered how individuals with chronic illnesses feel isolated (Kashikar-Zuck et al., 2007), have interruptions in school (e.g., Pini et al., 2012), and a decrease in the number of friends (e.g., Mattsson et al., 2007). We do know, however, that emerging adults are more likely to develop relationships with a variety of people in order to gain a better understanding of who they are as a person and what they want in the future (Arnett, 2004). This suggests that, compared to younger individuals, emerging adults may be more willing to form a relationship with a peer who has cancer, but there is no existing research that confirms this supposition. Therefore, it could be used by health professionals to aid in decreasing assumptions that a cancer diagnosis results in fewer peers. 
This study attempts to fill the considerable gaps in the literature regarding the role chronic illness and physical appearance has on the emerging adult peer relationship. Peers become a stable influence in the lives of emerging adults (Arnett, 2000; Pascarella \& Terenizini, 1991), so it is critical that influences on peer acceptance among emerging adults are studied. Further, because of the large number of cancer diagnoses in this age group, it is important to understand how the physical symptoms (e.g., hair loss) of cancer treatment impacts peers during this developmental period. Therefore, the purpose of this study is to examine and compare emerging adults' perceptions of peers who appear to be undergoing chemotherapy for cancer treatment and those who are healthy by using four vignettes of hypothetical peers: two vignettes portraying healthy peers and two vignettes portraying peers who look as if they are undergoing chemotherapy treatments for cancer. Three hypotheses will be tested:

Hypothesis 1: Participants will rate the models who appear to be undergoing chemotherapy as having lower peer acceptance scores compared to the healthy models. Hypothesis 2: The female model who appeared to be undergoing chemotherapy will receive higher peer acceptance ratings as compared to the male model who appeared to be undergoing chemotherapy.

Hypothesis 3: Participants with a chronic illness will rate the hypothetical peers more positively compared to participants without a chronic illness.

Hypothesis 4: There will be a positive relationship between the number of people participants know who have had cancer and participant ratings of peer acceptance. 


\section{Chapter III}

\section{Theoretical Framework}

Bronfenbrenner's ecological theory can help provide a basis for understanding the importance peers play to an individual as well as how a cancer diagnosis may impact that individual. Ecological theory attempts to explain the interaction between a person and their surrounding environments, both direct and indirect (Bronfenbrenner, 1979). According to this theory, a person's overall ecological system is made up of five nested subsystems: microsystem (the immediate environments), mesosystem (interactions between microsystems), exosystem (indirectly influences a microsystem), macrosystem (characteristics of the culture), and chronosystem (change or lack thereof over time; Bronfenbrenner, 1994). Every system is influenced by the interactions of the broader environments above it (Bronfenbrenner, 1979). For example, the macrosystem affects the exosystem, which in turn affects the microsystem and therefore influences the individual. For the purpose of this study, the microsystem and chronosystem will be more closely examined, as the immediate environment of an individual (e.g. peers) and change(s) over time (e.g. cancer diagnosis) will be most relevant.

\section{Microsystem}

A microsystem system is an immediate environment experienced by the individual. More specifically, it is defined as:

A pattern of activities, social roles and interpersonal relations experienced by the developing person in a given face-to-face setting with particular physical, social, and symbolic features that invite, permit, or inhibit engagement in sustained, progressively more complex interaction with, and activity in, the immediate environment.

(Bronfenbrenner, 1994, pp. 39) 
Examples of microsystem settings are work, home, daycare, and school, including the individuals belonging to those settings (e.g. co-workers, parents, preschool directors, teachers, respectively; Bronfenbrenner, 1994). The interactions that the individual has with the immediate environment can trigger development as well as maintain it (Bronfenbrenner, 1994). The particular microsystems that a person partakes in is guided by their individual characteristics. For example, in the context of emerging adults, college is a microsystem, which provides hours of face-to-face contact with their peers.

Influence of Peers. Researchers readily agree that peers are influential in the development of an individual. Peer relationships provide individuals with help, models for selfreferencing, sources of approval (Klima \& Repetti, 2008), and a way to learn about their self (Engle, McElwain, \& Lasky, 2011). Numerous studies have shown that relationships with one's peers have an impact on social development. Dykas et al. (2008) found that adolescents who thought of their peers negatively were more often perceived as bullied and not socially accepted by their peers compared to adolescents who viewed their peers positively, meaning that peer perceptions are influential in overall peer acceptance. Furthermore, peers provide social referencing for the future. As individuals progress from childhood to adolescence, the increase in intimacy amongst their peer relationships provides them with tools to interact with their peers later in life (Collins \& Laursen, 2004).

Studies have shown that individuals who have been rejected by their peers are at risk for negative externalizing and internalizing behaviors. Studies have shown that aggression and peer rejection are significant predictors of later adjustment in adolescence (Coie, Lochman, Terry, \& Hyman, 1992) and in adulthood (Parker \& Asher, 1987). Furthermore, lower peer acceptance was positively correlated with dropping out of school (Parker \& Asher, 1987). On the other hand, 
lower rates of peer rejection combined with the presence of at least one mutual friend in fifth grade predicted positive adult adjustment (Bagwell et al., 1998).

In a study on early childhood peer interactions on later social competence, it was found that positive peer interactions during early childcare resulted in lower aggression, less isolation from other peers, and better social skills in third grade (National Institute of Child Health and Human Development Early Child Care Research Network, 2008). Children who were socially accepted by their peers in fifth grade were shown to adjust better to the middle school transition (Kingery et al., 2011). Adolescents have been shown to be less lonely if they are socially accepted by their peers (Woodhouse et al., 2012). One study found that peer acceptance was the mediating factor between inhibitory control and math achievement in early adolescent students (Oberle \& Schonert-Reichl, 2013).

Although much research has been produced emphasizing the influence of peers, little research has focused on the influence of peers on emerging adults. According to Arnett (2007), emerging adults become less reliant on their peers due to the transition to college with the resulting decrease in number of friendships, likely interaction with a romantic partner, and more time spent alone, yet they are more of a stable influence than their family (Arnett, 2000). In addition, Steinberg and Monahan (2007) assessed individuals' resistance to peer influence based on age differences and found that there is a linear increase, with a similar result shown for males and females. This would suggest that as a person ages there should be a greater resistance to their peer's influence, resulting in greater autonomy in decision-making. In contrast, in a study on reckless behaviors in emerging adults, peer pressure was found to be the strongest predictor of substance abuse and as a predictor of overall recklessness (Teese \& Bradley, 2008). Though an emerging adults' years are marked by the instability of their lifestyle (Arnett, 2004), peers 
become more of a direct influence during this time period compared to parents (Arnett, 2000; Pascarella \& Terenizini, 1991), suggesting a shift in the influences from microsystem. Despite this shift, research is lacking in the specifics of peers in emerging adulthood. This study aims to add to this research by studying peer acceptance in a sample of emerging adults.

\section{Chronosystem}

The broadest subsystem of Bronfenbrenner's ecological theory is called the chronosystem, which involves the changes or lack of change of the person and their environment at any given time (Bronfenbrenner, 1994). These changes, also called life transitions, can be separated into normative (e.g., starting college at 18) and nonnormative events (e.g., a cancer diagnosis; Bronfenbrenner, 1986). The nesting structure of the ecological model means that any life transitions experienced in the chronosystem will affect the individual's four other subsystems. For example, a child who is diagnosed with cancer (a nonnormative event within the chronosystem) is introduced to a new culture ("hospital culture;" Gillmor, 2001; change in the macrosystem). Further, the child's parents may have to take time off of work that may cause a strain at work (influence on the exosystem), and the added strain from the diagnosis and work may cause the parents to fight more (impact on the mesosystem). Finally, the child may not be able to spend as much or any time with his or her peers because of being in the hospital (change in the child's microsystem). Therefore, a nonnormative event within the chronosystem, such as cancer, can have an impact in the peer relationships of the individual.

Cancer as a chronic illness. According to the Center for Disease Control (CDC, 2013), $70 \%$ of deaths in the United States are from chronic diseases with over half of these deaths from heart disease, cancer, and strokes, combined. Furthermore, approximately 133 million Americans 
have at least one chronic illness, including, but not limited to, arthritis, obesity, diabetes, heart disease, and cancer.

According to the World Health Organization (WHO, 2013), chronic illnesses last for an extended period of time and progress slowly, which classifies cancer as such an illness. There are over 100 different types of cancers (ACS, 2013a; National Cancer Institute, 2013b) with a variety of treatments and side effects. There are three primary methods of treatment. The first method, radiation, is the use of high doses of radiation beams aimed directly at the cancer cells in the hopes of destroying the DNA of the unwanted cells, while leaving as many of the healthy cells as untouched as possible (ACS, 2013b; National Cancer Institute, 2013a). Side effects of radiation include, but are not limited to, skin irritation/damage, hair loss, nausea, fatigue, bleeding, and fibrosis. The presence and severity of these side effects depends on length of the treatment, location of the radiation, and dosage (National Cancer Institute, 2013a). Radiation therapy may be used alone or with other medical techniques to treat cancer. Surgery can also be used to diagnose and/or treat cancer, depending on the specific type of cancer diagnosis (ACS, 2013b). Depending on the type of cancer and the reason for surgery, possible side effects and/or permanent changes are: visible medical apparatuses, bleeding at the site of the incision, loss of limb, shaved body areas, and bruising. Finally, chemotherapy (or chemo) is the use of medications that travel throughout the entire body with the intent of attacking cancer cells, though inadvertently destroying healthy cells as well (ACS, 2013b). Chemo is typically administered via the patient's vein, also known as intravenous (IV) treatment) through a catheter, but other ways include through the patient's muscle, skin, spinal cord, mouth, or abdominal cavity. As with most cancer treatment, side effects are common for individuals taking chemotherapy with the presence of a particular side effect and its severity depends on the type of 
medication, dosage, and the patient. Common characteristics for individuals taking chemo include hair loss, bleeding, nausea, skin and nail changes, bruising, weight gain, and mouth, gum, and throat problems (ACS, 2013b; National Cancer Institute, 2013a).

Studies have yet to specifically focus on emerging adults with cancer; rather, many studies look at adolescents (e.g., Gray \& Rodrigue, 2001), young adults (e.g., Bellizzi et al., 2012), or both (e.g., Carpentier, Fortenberry, Ott, Brames, \& Einhom, 2010). It should be noted that many studies used participants that were developmentally labeled as adolescent or young adult, but the range of participants' ages sometimes overlapped into emerging adulthood, such as Bellizzi et al. (2012) and Carpentier et al. (2010) with an age range of 15 to 39 years old and 18 to 34 years old, respectively. Emerging adulthood is characterized by instability, and it is likely that a cancer diagnosis would only accentuate this because of the nonnormative transition. In addition to changing living situations, schools, and jobs typical of an emerging adult, a cancer diagnosis would involve possible frequent hospitalizations and doctors' office visits, interacting with a variety of people (doctors, nurses, therapists, etc.), and altering one's daily schedule based on health. Furthermore, Arnett (2004) proposed that emerging adults are attempting to define their identity by exploring possibilities. A cancer diagnosis may limit potential possibilities for emerging adults to explore, which may alter their identity development. Finally, because peer relationships remain essential to the emerging adult, a cancer diagnosis may interfere with existing friendships or the likelihood of creating new ones, though no researchers have focused on the microsystem (peer relationships) and chronosystem (cancer diagnosis) influences among emerging adults. Thus, this study seeks to fill this gap in the literature. 


\section{Chapter IV}

\section{Method}

Cancer treatments can leave physical side effects on patients. For example, chemotherapy can result in hair loss, skin changes (such as paleness), bruises, and weight gain (ACS, 2013b; National Cancer Institute, 2013a). Research on physical appearance and peer acceptance suggests that individuals who are physically attractive are accepted more often than those who are not perceived as attractive (Lansu \& Cillessen, 2012; Vannatta et al., 2009; Zakin, 1983). Physical appearance and peer acceptance in the context of cancer has yet to be examined in current research, therefore it is the purpose of the study to add to this area by comparing peer acceptance of an emerging adult who appears to be undergoing chemotherapy to an emerging adult who appears healthy.

\section{Participants}

For this cross-sectional design, participants were recruited from West Virginia University via a posted announcement through the university's MIX electronic announcement system. Participants outside of the $18-25$ year-old age range were informed they did not meet the requirements of the study and were removed from the survey, as they were not considered within the age range of emerging adulthood (Arnett, 2000; 2002; 2004; 2007; Montgomery, 2005). A total of 182 participants completed the survey. The mean student age was 20.85 years $(\mathrm{SD}=$ 1.89 ; range $=18-26)$, with majority of the sample female $(79 \%)$. Furthermore, the sample was predominantly Caucasian (87\%; Asian: 5\%; More than one race: 4\%; Other: 4\%; Black/AfricanAmerican and American Indian/Alaska Native: each less than 1\%). Few of the participants had a chronic illness (11\%). In addition, only 13 of the participants had never known anyone with cancer. Two participants had cancer, 56 had an immediate family member with cancer, 109 had 
an extended family member who had/has cancer, 80 had a friend with cancer, and 79 knew an acquaintance with cancer.

\section{Procedure}

After obtaining approval from West Virginia University's Institutional Review Board, the vignettes and accompanying measures were created using Qualtrics, a program that allows for the creation of online surveys. An advertisement for the study was posted on West Virginia University's MIX electronic announcement system that invited students to participate in a research project, with the incentive of winning a gift card. The ad included a link for interested participants to access the survey. The link was active for students approximately two weeks.

Upon clicking the link to access the survey, participants read a letter of consent (see Appendix A). They read a short description of the study, were told that it will take approximately ten minutes to complete, and that participation is voluntary. They also were informed that they can exit the survey at anytime without penalty. Finally, they were told that by clicking the "yes" button indicates their consent to participate in the study. Then, they were directed to three questions, which determined their eligibility to take the survey. The participant was asked if they were between the ages of 18 and 25 , if they were married, and if they had a child(s). If the participant was not between 18 and 25 and/or if they were married and/or if they had a child, they were automatically exited out of the survey. Few participants did not qualify for the study (17), all of whom were outside of the age range. Next, each participant was randomly directed to one of the four vignettes. Participants were fairly evenly distributed across all four vignettes (47 healthy female; 43 healthy male; 44 chemotherapy female; 48 chemotherapy male). Students were asked to look at the picture, read the accompanying description, and answer the Peer Acceptance Measure. 
The students were then directed to a third page to complete five demographic items (see Appendix B). They were asked to list their age, sex, race, high school graduating class size, and previous exposure to individuals with cancer. To indicate their previous exposure to individuals with cancer, participants were asked to check all that apply: self, immediate family member, extended family member, friend, acquaintance, or none. Lastly, participants who wanted to be considered for the gift card drawings were asked to provide an email address, which was not connected to their data. The winners were selected at random at the conclusion of the study.

\section{Vignettes}

Four vignettes, each describing a hypothetical peer, were developed based on research using vignettes (Gray \& Rodrigue, 2001; King et al., 2010). Two vignettes depicted healthy peers, and the other two vignettes depicted peers who appear to be undergoing chemotherapy treatment for cancer. Each vignette consisted of a picture and a small explanation of how the model interacts with the participant. As with previous studies, the models in the vignettes and the participants are of the same age group. Both sexes are also represented: two male vignettes and two female vignettes (Gray \& Rodrigue, 2001; King et al., 2010). One male and one female model were used for each vignette type. To ensure the pictures used for the vignettes were age appropriate, an undergraduate class of CDFS 112: Introduction to Marriage and Families was given a photo of the male model and asked, "How old (in years) do you think this person is?" The same was done for the female model. The mean reported ages for the male and female models were $19.22(\mathrm{SD}=1.42)$ and $19.96(\mathrm{SD}=1.30)$, respectively.

Of the four vignettes, two portrayed a healthy looking male and female and two portrayed the same male and female looking as if they were currently undergoing treatment for cancer (i.e., the chemotherapy vignettes). The photos, which depicted the models undergoing chemotherapy, 
were edited using a computer software program that allowed the users to make the models appear bald. In addition, make-up was put on the models to make them appear paler and more tired for the photos that would be used to portray them undergoing chemotherapy treatment for cancer (e.g., sunken eyes). The final edited photos were shown side-by-side to a second undergraduate class of CDFS 112: Introduction to Marriage and Families. The students were asked to answer the question, "What do you assume about these persons' health?" Responses included both of the models have cancer (61.54\%), (unrelated to their health) shaved their heads (15.38\%), only the girl has cancer (7.69\%) a genetic problem (7.69\%), and general sickness $(7.69 \%)$.

Accompanying each picture was a small paragraph explaining how the participant knows the hypothetical student. Two separate written vignettes were used: one for the healthy models and one for the models who look as if they are suffering the effects of chemotherapy. After viewing the picture and reading the vignettes, participants were asked to complete 16 items (fifteen Likert items and one yes or no question) assessing peer acceptance and their perceptions. Below are examples of the written portion of the vignette for the models who look healthy and who look as if they are undergoing chemotherapy treatment, respectively (See Appendices C-F for examples of all four vignettes):

Healthy Model Written Vignette

This is a college student at a university similar to West Virginia University. S/he attended college after s/he graduated high school when s/he was 18 . S/he wasn't sure what to major in when s/he began college, but has recently decided on what $\mathrm{s} / \mathrm{he}$ thinks s/he wants to do after graduation. Even though $\mathrm{s} / \mathrm{he}$ graduated from high school not that long ago, s/he feels older and different than most adolescents 
still in high school. Further, even though a lot of people call him/her an adult, s/he doesn't quite feel like an adult. S/he has some anxiety about what s/he'll do after graduation, but also is excited for what may happen after college. Outside of typical sicknesses (e.g., colds, flus), s/he has been healthy for most of his/her life. Rarely has s/he missed school because of sickness, and s/he seldom has missed college classes because of illness.

Chemotherapy Model Written Vignette

This is a college student at a university similar to West Virginia University. S/he attended college after s/he graduated high school when s/he was 18 . S/he wasn't sure what to major in when s/he began college, but has recently decided on what $\mathrm{s} /$ he thinks s/he wants to do after graduation. Even though s/he graduated from high school not that long ago, s/he feels older and different than most adolescents still in high school. Further, even though a lot of people call him/her an adult, s/he doesn't quite feel like an adult. S/he has some anxiety about what s/he'll do after graduation, but also is excited for what may happen after college. S/he has been diagnosed with cancer and is currently undergoing treatments, which have caused him/her to lose his/her hair. S/he often feels sick and/or tired, but wants to attend class as often as s/he can. Unfortunately, because of his/her treatments and how $\mathrm{s} / \mathrm{he}$ feels afterwards, $\mathrm{s} / \mathrm{he}$ has missed school often because of sickness.

\section{Peer Acceptance Measure}

Fifteen questions on a 5-point Likert scale were developed specifically for this study to assess peer acceptance of the vignettes. The items asked the likeliness of the model's hypothetical peers' (i.e. the participants) willingness to engage in a number of activities with the 
model as well as items measuring the extent to which participants believe that the model's physical appearance influences peer acceptance. Participants were asked to respond from the model's hypothetical peers points of view because previous research has indicated that personally held and cultural stereotypes have been found to highly correlate (Gordijn, Koomen, \& Stapel, 2001). Participants were asked to complete each statement with the following scale: 1 for none, 2 for few, 3 for some, 4 for most, and 5 for all. Example items include: “__ of this person's classmates ask them to go to a coffee shop after class," and of this person's classmates are comfortable with their physical appearance."

To check for content validity, the measure was assessed by seven, five-participant focus groups who were in an upper-level undergraduate class, CDFS 413: Contemporary Issues in Family Studies. The class was made up of emerging adults between the ages of 19-26 (M= 21.30; $\mathrm{SD}=1.31$ ). Students were asked to read each item and determine if it was an acceptable measure of peer acceptance. If not, they were asked to provide an explanation. In addition, it was requested that each student make suggestions of other ways peer acceptance could be measured. Two items from the original peer acceptance measure were removed after the focus group was conducted. The peer acceptance items “___ of this person's classmates would want to work out together outside of class” and “___ of this person's classmates would want to grab dinner and/or drinks outside of class" were removed based on a $66 \%$ and $50 \%$ rejection, respectively. The items were replaced with "___ of this person's classmates want to sit near them in class" and “___ of this person's classmates want to pick this person as a partner in class." The resulting peer acceptance measure (see Appendix $G)$ was reliable $(\alpha=.86)$.

\section{Data Analysis}


After the survey is closed, the data was downloaded into Microsoft Excel, and then uploaded into SPSS for analysis. In order to test the four hypotheses, ANOVAs (hypotheses 1 and 2), independent t-tests (hypothesis 3), and a bivariate correlation (hypothesis 4) were run and descriptive data were obtained. 


\section{Chapter V}

\section{Results}

\section{Hypotheses 1 and 2}

The first hypothesis was that participants would rate the models who appeared to be undergoing chemotherapy as having lower peer acceptance scores compared to the healthy models. A second, and related, hypothesis was that the female model who appeared to be undergoing chemotherapy would receive higher peer acceptance ratings as compared to the male model who appeared to be undergoing chemotherapy. These hypotheses were tested using a oneway between subjects ANOVA with the type of the hypothetical peer (i.e., healthy female, healthy male, unhealthy female, unhealthy male) as the independent variable and peer acceptance as the dependent variable.

This analysis revealed that there were significant differences in peer acceptance among the four types of hypothetical peers, $F(3)=4.79, p=.003$. Post hoc comparisons using the Tukey HSD test provided partial support for the first hypothesis. The mean peer acceptance score for the healthy female hypothetical model $(\mathrm{M}=3.46 ; \mathrm{SD}=.47)$ was significantly higher than the peer acceptance scores of the healthy male model $(\mathrm{M}=3.34 ; \mathrm{SD}=.61)$ and the chemotherapy male model $(\mathrm{M}=3.19 ; \mathrm{SD}=.48)$ and was trending toward significance in comparison to the chemotherapy female model $(\mathrm{M}=3.08 ; \mathrm{SD}=.50)$. The healthy male model was not significantly different than either of the chemotherapy models. The second hypothesis was not supported.

\section{Hypothesis 3}

The third hypothesis was that participants with a chronic illness would rate the hypothetical peers more positively compared to participants without a chronic illness. This hypothesis was tested using a t-test with the chronic illness of the participant as the independent 
variable and peer acceptance as the dependent variable. This analysis revealed that there were no significant differences in perceptions, $t(180)=-.95, p=.35$.

\section{Hypothesis 4}

The fourth hypothesis was that there would be a positive relationship between the number of people participants knew who had cancer and participant ratings of peer acceptance. This hypothesis was tested by examining a bivariate correlation between these two continuous variables. This analysis indicated that there was a significant weak positive association, meaning that when the number of individuals that participants knew who had cancer was high, peer acceptance scores were also high $(r=.20, p=.01)$. 


\section{Chapter VI}

\section{Discussion}

The intent of this study was to study how physical appearance influences perceived peer acceptance of healthy individuals and individuals who appeared to be undergoing chemotherapy, using picture vignettes and a survey. The four hypotheses of this study are explained and interpreted below.

\section{Hypothesis 1}

Previous work suggests that physical appearance is a strong indicator of peer acceptance (Lansu \& Cillessen, 2012; Vannatta et al., 2009; Zakin, 1983). Based on this research, it was predicted that participants would rate the models who appeared to be undergoing chemotherapy as having a lower peer acceptance rating as compared to the models who appeared to be healthy. Results showed that the healthy female model received significantly higher peer acceptance ratings when compared to the healthy male model and the chemotherapy male model. This suggests that individuals are more likely to perceive healthy looking females as receiving greater acceptance from their peers as compared to males, regardless of their physical appearance. This may mean that females who appear physically normal have more microsystem support from peers compared to males despite their physical appearance. Therefore, programs may need to be implemented into early education to foster more microsystem peer acceptance for males. In this way, when a nonnormative event occurs, more social support might be provided for males.

Furthermore, though not significant, both healthy models received higher peer acceptance score means $($ females $=3.46$; males $=3.34)$ compared to both chemotherapy models $($ females $=$ 3.08; males $=3.18$ ). Although interpretation of these particular ratings should be made with care, it is important to note that individuals who are undergoing chemotherapy are assumed to have 
lower levels of peer acceptance, which may lead individuals to believe cancer patients have little social support. This belief could have important ramifications for individuals who are diagnosed with cancer, as they may believe they will become social outcasts. In order to proactively combat this assumption, awareness programs could be executed on university campuses to decrease the prevalence of such assumptions. In addition, health professionals (e.g., nurses, therapists, etc.) could facilitate small groups for these emerging adults to encourage peer social support with new aspects of their microsystems.

\section{Hypothesis 2}

Although it was hypothesized that participants would perceive the female model who appeared to be undergoing chemotherapy more positively than the male model who appeared to be undergoing chemotherapy, this finding was not significant. This is in contrast to other research, which has provided support for the assertion that females are perceived more positively than males (Gray \& Rodrigue, 2001). It may be that, at least among this sample, individuals perceive both men and women who are undergoing chemotherapy as similarly struggling with being accepted by their peers.

It should be noted that mean difference ratings in peer acceptance between the healthy female hypothetical model and the chemotherapy female model approached significance. Furthermore, when peer acceptance scores were compared across all four models, the female model who appeared to be undergoing chemotherapy had the lowest score, while the healthy female model had the highest. This indicates that change in physical appearance can be more detrimental in terms of peer acceptance for females than for males, though further research with a larger sample is needed to explore this possibility. Previous researchers have found that looking different than their peers was more harmful in terms of self-worth for women than men 
(Davison \& McCabe, 2006). Thus, while no significant differences between unhealthy males' and unhealthy females' peer acceptance scores were found in this study, it may be that the appearance changes associated with chemotherapy is more harmful to women's self-esteem or other personal assessments, which would be a beneficial topic for further study. If this is case, then health professionals need to be aware of the impact that this could have women's mental health and be prepared to encounter accompanying issues.

\section{Hypothesis 3}

Bronfenbrenner's theory states that a change in a person's chronosystem (e.g., chronic illness) can influence the four other nested systems (e.g., peer relationships in the microsystem; Bronfenbrenner, 1994). Therefore, it was expected that participants with a chronic illness would be more accepting of the hypothetical peers compared to participants without a chronic illness. Significant differences were not found for this hypothesis. It could be that "chronic illness" was too broad a term. Participants may classify conditions that do not impede normal body functioning (e.g., eczema) as chronic illnesses. Although these conditions would be classified as chronic illnesses, they likely would have a different impact compared to a chronic illness that does impact normal body functioning on a daily basis (e.g., diabetes). Taken a different way, chronic illnesses that impact physical appearance (e.g., cancer) may lead to different influences on the perceptions of peer acceptance than chronic illnesses that do not impact physical appearance (e.g., celiac disease). In other words, individuals that have a chronic illness that alters their physical appearance may be more accepting of peers who are physically different, whereas individuals who have a chronic illness with no impact on their physical appearance may have lower peer acceptance of those who appear different. Further, it could be that the severity of the 
variety of chronic illnesses would differently impact individuals' ratings of peer acceptance because of the likely integration with a new chronosystem (e.g., hospital culture; Gillmor, 2001).

\section{Hypothesis 4}

Given that the chronosystem impacts the four other systems and that a person's microsystem has the ability to elicit and sustain development (Bronfenbrenner, 1994), it was predicted that a positive relationship would exist between the number of people the participants knew who had cancer and their peer acceptance ratings. Results revealed that there was a positive correlation between the number of people the participants knew who had cancer and peer acceptance ratings, meaning that the more people that the participant knew who had cancer the higher the peer acceptance scores. This result is not surprising given that a cancer diagnosis is an example of a non-normative event within the chronosystem, which can change the microsystem characteristics. In this study, only 13 participants had a microsystem not influenced by cancer. The remaining 169 had a microsystem that was influenced by cancer, sometimes heavily so in the case of individuals who had/has a family member (immediate and extended) with cancer and who had/has a friend and acquaintance with cancer. This suggests that as cancer increasingly impacts individuals' microsystems, they become more sensitive to people undergoing chemotherapy. Therefore, emerging adults with low exposure to cancer in their microsystems could be encouraged to volunteer at local hospitals in order increase their understandings of and sensitivity to individuals undergoing chemotherapy.

\section{Limitations and Future Directions}

This study adds to the existing literature on the impact of physical appearance on peer relationships by examining physical appearance in the context of a chronic illness with emerging 
adults. However, continued research in this area is needed to distinguish the multiple influences that an altered physical appearance from a chronic illness has on peer relationships.

Gender bias. Majority of the participants in this study were female (79\%), which might account for why the healthy female model had the highest peer acceptance score. The homophily principle proposes that individuals identify with others whom they perceive to be similar to themselves. Therefore, as the demographic data shows, majority of the sample would relate to the healthy female model due to gender (79\%), not personally having had cancer $(98.90 \%)$, and/or $89 \%$ not having a chronic illness. Therefore, in regards to a gender bias of the sample, future studies should attempt to control for gender.

Generalizability. Generalizations should be made with care. The sample only consisted of emerging adults attending college, which indicates middle to upper class. Furthermore, as indicated above, majority of the participants were female. Therefore, in future research, a larger sample size across various emerging adults types (students, single working adults, etc.) of varying social classes will strengthen the generalizability.

Mixed-methods study. This study used a 5-point Likert scale peer acceptance measure to gain quantitative data from methods, but future endeavors should consider utilizing qualitative methods as well. It could be that emerging adults without cancer answered items in the measure based on their perception of the hypothetical chemotherapy model's ability to engage social activities. For example, is the hypothetical chemotherapy peer feeling well enough to spend time with participant's friends outside of class? Qualitative data would provide the opportunity for the emerging adults without cancer to explain their reasoning for indicating specific levels of peer acceptance. 
Utilization of video vignettes. The current study portrayed the hypothetical peers through picture and written vignettes in order to give a visual portrayal and establish history with the participant. It might be beneficial to create video vignettes in which actors with cancer portray the hypothetical peers on pre-recorded videos, as previously done by Gray and Rodrigue (2001). Compared to the present study, the use of a video vignette would provide a more realistic interaction of peer relationships with the hypothetical peer providing verbal and non-verbal cues. This would allow for the participant to have better awareness of the peer and therefore to answer more accurately on peer acceptance measures.

\section{Conclusions}

Regardless of their physical appearance, males receive lower peer acceptance when compared to healthy looking females. Furthermore, the number of people that a person knows with cancer affects how their peer acceptance of someone who looks different. More specifically, the more people they know, the more likely they are to accept a person who looks different. A person's physical appearance has been found to be a strong influence in peer acceptance (Lansu \& Cillessen, 2012; Vannatta et al., 2009; Zakin, 1983). Despite the stable influence of peers during this developmental period (Arnett, 2000; Pascarella \& Terenizini, 1991), there remains a gap in knowledge in the peer relationships of emerging adults. This study added to that literature by finding that physical appearance could have an impact on the peer acceptance of emerging adults. With the normative and nonnormative events of the chronosystem occurring throughout each person's life span, changes occur which include physical changes of the individual. By studying the impact of physical appearance on peer acceptance, professionals could better equipment school curriculum, other professionals, and parents to handle this influence. In addition, a positive relationship exists between the microsystem exposure to cancer and peer 
acceptance ratings. It is important that physical appearance is examined in the context of a chronic illness due to the large number of people affected (133 million; CDC, 2013) and the affect it has on their ecological systems. Future research should continue pursue how physical appearance in the context of a chronic illness influences peer acceptance. 


\section{References}

American Cancer Society. (2013a). Learn about cancer. Retrieved from http:// http://www.cancer.org/cancer/index.

American Cancer Society. (2013b). Find support \& treatment. Retrieved from http:// http://www.cancer.org/treatment/index.

Arnett, J. J. (2000). Emerging adulthood: A theory of development from the late teens through the twenties. American Psychologist, 55(5), 469-480.

Arnett, J. J. (2002). Emerging adulthood: A theory of development from the late teens through the twenties. American Psychologist, 55, 469-480.

Arnett, J. J. (2004). Emerging adulthood: The winding road from the late teens through the twenties. New York, New York: Oxford University Press.

Arnett, J. J. (2007). Socialization in emerging adulthood: From the family to the wider world, from socialization to self-socialization. In J. E. Grusec \& P. D. Hastings (Eds.), Handbook of socialization: Theory and research (pp. 208-231).

Badaly, D., Schwartz, D., \& Gorman, A. H. (2012). Social status, perceived social reputations, and perceived dyadic friendships in early adolescence. Social Development, 21(3), 482500.

Bagwell, C. L., Newcomb, A. F., \& Bukowski, W. M. (1998). Preadolescent friendship and peer rejection as predictors of adult adjustment. Child Development, 69(1), 140-153.

Bellizzi, K. M., Smith, A., Schmidt, S. Keegan, T. H., Zebrack, B., Lynch, C. F., Deapen, D., Shnorhavorian, M., Tompkins, B. J., Simon, M., \& the Adolescent and Young Adult Health Outcomes and Patient Experience [AYA HOPE] Study Collaborative Group. 
(2012). Positive and negative psychosocial impact of being diagnosed with cancer as an adolescent or young adult. Cancer, 118(20), 5155-5162.

Benner, A. E., \& Marlow, L. S. (1991). The effect of a workshop on childhood cancer on students' knowledge, concerns, and desire to interact with a classmate with cancer. Children's Health Care, 20(2), 101-107.

Bronfenbrenner, U. (1979). The ecology of human development: Experiments by nature and design. Massachusetts: Harvard University Press.

Bronfenbrenner, U. (1986). Ecology of the family as a context for human development: Research perspectives. Developmental Psychology, 22(6), 723-742.

Bronfenbrenner, U. (1994). Ecological models of human development. In International Encyclopedia of Education (pp. 1643-1647). Oxford: Elsevier.

Carpentier, M. Y., Fortenberry, J. D., Ott, M. A., Brames, M. J., \& Einhom, L. H. (2010). Perceptions of masculinity and self-image in adolescent and young adult testicular cancer survivors: Implications for romantic and sexual relationships. Psycho-Oncology, 20, 738745.

Center for Disease Control and Prevention. (2013). Chronic diseases and health promotion. Retrieved from http:// http://www.cdc.gov/chronicdisease/overview/index.htm.

Chekryn, J., Deegan, M., \& Reid, J. (1986). Normalizing the return to school of the child with cancer. Journal of the Association of Pediatric Oncology Nurses, 3(2), 20-24, 34.

Coie, J. D., Lochman, J. E., Terry, R., \& Hyman, C. (1992). Predicting early adolescent disorder from childhood aggression and peer rejection. Journal of Consulting and Clinical Psychology, 60(5), 783-792. 
Collins, W. A., \& Laursen, B. (2004). Changing relationships, changing youth: Interpersonal contexts of adolescent development. Journal of Early Adolescence, 24(1), 55-62.

Copen, C. E., Daniels, K., Vespa, J., \& Mosher, W. D. (2012). First marriages in the United States: Data from the 2006-2010 national survey of family growth. National Health Statistics Report, 49, 1-21.

Davison, T. E., \& McCabe, M. P. (2006). Adolescent body image and psychosocial functioning. The Journal of Social Psychology. 146(1), 15-30.

Deasy-Spinetta, P. (1993). School issues and the child with cancer. Cancer, 71(10), 3261- 3264.

Dykas, M. J., Ziv, Y., \& Cassidy, J. (2008). Attachment and peer relations in adolescence. Attachment \& Human Development, 10(2), 123-141.

Engle, J. M., McElwain, N. L., \& Lasky, N. (2011). Presence and quality of kindergarten children's friendships: Concurrent and longitudinal associations with child adjustment in the early school years. Infant \& Child Development, 20(4), 365-386.

Enskar, K., Carlsson, M., Golsater, M., \& Hamrin, E. (1997). Symptom distress and life situation in adolescents with cancer. Cancer Nursing, 20(1), 23-33.

Gerhardt, C. A., McGoron, K. D., Thompson, A. L., Vannatta, K., McNamara, K. A., Taylor, J., Passo, M. H., \& Noll, R. B. (2011). Social outcomes among emerging adults with Juvenile Idiopathic Arthritis. Children's Health Care, 40, 70-84.

Gillen, M. M., \& Lefkowitz, E. S. (2009). Emerging adults' perceptions of messages about physical appearance. Body Image, 6(3), 178-185.

Gillmor, M. (2001). The hospital: A foreign culture. International Journal of Childbirth Education, 16(1), 18-19. 
Glasson, J. E. (1995). A descriptive and exploratory pilot study into school re-entrance for adolescents who have received treatment for cancer. Journal of Advanced Nursing, 22, $753-758$.

Gordijn, E. H., Koomen, W., \& Stapel, D. A. (2001). Level of prejudice in relation to knowledge of cultural stereotypes. Journal of Experimental Social Psychology, 37, 150-157.

Gray, C. C., \& Rodrigue, J. R. (2001). Brief report: Perceptions of young adolescents about a hypothetical new peer with cancer. Journal of Pediatric Psychology, 26(4), 247-252.

Hamilton, S. F. (1994). Employment prospects as motivation for school achievement: Links and gaps between school and work in seven countries. In R. K. Silbereisen \& E. Todt (Eds.), Adolescence in context: The interplay of family, school, peers, and work in adjustment (pp. 267-283). New York: Spring-Verlag.

Iobst, E. A., Ritchey, P. N., Nabors, L. A., Stutz, R., Ghee, K., \& Smith, D. T. (2009). Children's acceptance of a peer who is overweight: Relations among gender, age and blame for weight status. International Journal of Obesity, 33, 736-742.

Kashikar-Zuck, S., Lynch, A. M., Graham., T. B., Swain, N. F., Mullen, S. M., \& Noll, R. B. (2007). Social functioning and peer relationships of adolescents with juvenile fibromyalgia syndrome. Arthritis \& Rheumatism, 57(3), 474-480.

King, S., MacDonald, A. J., \& Chambers, C. T. (2010). Perceptions of healthy children toward peers with a chronic condition. Children's Health Care, 39, 199-213.

Kingery, J. N., Erdley, C. A., \& Marshall., K. C. (2011). Peer acceptance and friendship as predictors of early adolescents' adjustment across the middle school transition. MerrillPalmer Quarterly, 57(3), 215-243. 
Klima, T., \& Repetti, R. L. (2008). Children's peer relations and their psychological adjustment: Differences between close friendships and the larger peer group. Merrill-Palmer Quarterly, 54(2), 151-178.

Lansky, S. B., Cairns, N. U., \& Zwartjes, W. (1983). School attendance among children with cancer: A report from two centers. Journal of Psychosocial Oncology, 1(2), 75-82.

Lansu, T. A. M., \& Cillessen, A. H. N. (2012). Peer status in emerging adulthood: Associations of popularity and preference with social roles and behavior. Journal of Adolescent Research, 27(1), 132-150.

Lyu, M., \& Gill, D. (2012). Perceived physical competence and body image as predictors of perceived peer acceptance in adolescents. Asian Journal of Social Psychology, 15(1), 3748.

Mattsson, E., Ringnér, A., Ljungman, G., \& von Essen, L. (2007). Positive and negative consequences with regard to cancer during adolescence. Experiences two years after diagnosis. Psycho-Oncology, 16(11), 1003-1009.

Meltzer, L. J., \& Rourke, M. T. (2005). Oncology summer camp: Benefits of social comparison. Children's Health Care, 34(4), 305-314.

Montgomery, M. J. (2005). Psychosocial intimacy and identity: From early adolescence to emerging adulthood. Journal of Adolescent Research, 20(3), 346-374.

National Cancer Institute. (2012a). A snapshot of adolescent and young adult cancers. Retrieved from http://www.cancer.gov/researchandfunding/snapshots/adolescent-young-adult.

National Cancer Institute. (2012b). SEER cancer statistics review, 1975-2009. Retrieved from http://seer.cancer.gov/csr/1975_2009_pops09/index.html. 
National Cancer Institute. (2013a). Cancer topics. Retrieved from http:// http://www.cancer.gov/cancertopics.

National Cancer Institute. (2013b). Defining cancer. Retrieved from http:// http://www.cancer.gov/cancertopics/cancerlibrary/what-is-cancer.

National Center for Education Statistics. (2011). Average daily attendance (ADA) as a percentage of total enrollment, school day length, and school year length in public schools, by school level and state: 2003-04 and 2007-08. Retrieved from http:/http://nces.ed.gov/programs/digest/d11/tables/dt11_043.asp.

National Institute of Child Health and Human Development Early Child Care Research Network. (2008). Social competence with peers in third grade: Associations with earlier peer experiences in childcare. Social Development, 17(3), 419-453.

Newsom, D., Mallow, J., Watson, J., Miner, A., Legg, K., \& Theeke, L. (In press). Loneliness in school age children: An integrative review of quantitative studies. Manuscript submitted for publication.

Noll, R. B., LeRoy, S., Bukowski, W. M., Rogosch, F. A., \& Kulkarni, R. (1991). Peer relationships and adjustment in children with cancer. Journal of Pediatric Psychology, 16(3), 307-326.

Oberle, E., Schonert-Reichel, K. A., \& Thomson, K. C. (2010). Understanding the link between social and emotional well-being and peer relations in early adolescence: Gender-specific predictors of peer acceptance. Journal of Youth \& Adolescence, 39(11), 1330-1342.

Oberle, E., \& Schonert-Reichel, K. A. (2013). Relations among peer acceptance, inhibitory control, and math achievement in early adolescence. Journal of Applied Developmental Psychology, 34(1), 45-51. 
Parker, J. G., \& Asher, S. R. (1987). Peer relations and later personal adjustment: Are lowaccepted children at risk? Psychological Bulletin, 102(3), 357-389.

Parker, J. G., \& Asher, S. R. (1993). Friendship and friendship quality in middle childhood: Links with peer group acceptance and feelings of loneliness and social dissatisfaction. Developmental Psychology, 29(4), 611-621.

Parker, J. G., \& Seal, J. (1996). Forming, losing, renewing, and replacing friendships: Applying temporal paramters to the assessment of children's friendship experiences. Child Development, 67, 2248-2268.

Parker, L. E., \& Pinkus, R. T. (2009). Interpersonal effects of appearance-based rejection sensitivity. Journal of Research in Personality, 43, 602-612.

Pascarella, E. T., \& Terenzini, P. T. (1991). How college affects students: Findings and insights from twenty years of research. San Fransisco: Jossey-Bass Publishers.

Pendley, J. S., Dahlquist, L. M., \& Dreyer, Z. (1997). Body image and psychosocial adjustment in adolescent cancer survivors. Journal of Pediatric Psychology, 22(1), 29-43.

Perry-Parrish, C., \& Zeman, J. (2011). Relations among sadness regulation, peer acceptance, and social functioning in early adolescence: The role of gender. Social Development, 20(1), 135-153.

Pini, S., Hugh-Jones, S., \& Gardner, P. H. (2012). What effect does a cancer diagnosis have on the educational engagement and school life of teenagers? A systematic review. PsychoOnocology, 21(7), 685-694.

Pitt, C., Lavery, C., \& Wager, N. (2009). Psychosocial outcomes of bone marrow transplant for individuals affected by Mucopolysaccharidosis I Hurler Disease: Patient social competency. Child: Care, Health \& Development, 35(2), 271-280. 
Roberts, C. S., Turney, M. E., \& Knowles, A. M. (1998). Psychosocial issues of adolescents with cancer. Social Work in Health Care, 27(4), 3-18.

Seidah, A., \& Bouffard, T. (2007). Being proud of oneself as a person or being proud of one's physical appearance: What matters for feeling well in adolescence? Social Behavior and Personality, 35(2), 255-268.

Schultz, K. A. P., Ness, K. K., Whitton, J., Recklitis, C., Zebrack, B., Robison, L. L., Zeltzer, L., \& Mertens, A. C. (2007). Behavioral and social outcomes in adolescent survivors of childhood cancer: A report from the childhood cancer survivor study. Journal of Clinical Oncology, 25(24), 3649-3656.

Smith, R. L., Rose, A. J., \& Schwartz-Mette, R. A. (2010). Relational and overt aggression in childhood and adolescence: Clarifying mean-level gender differences and assocations with peer acceptance. Social Development, 19(2), 243-269.

Steinberg, L., \& Monahan, K. C. (2007). Age differences in resistance to peer influence. Developmental Psychology, 43(6), 1531-1543.

Teese, R., \& Bradley, G. (2008). Predicting recklessness in emerging adults: a test of a psychosocial model. The Journal of Social Psychology, 148(1), 105-126.

Vannatta, K., Garstein, M. A., Zeller, M., \& Noll, R. B. (2009). Peer acceptance and social behavior during childhood and adolescence: How important are appearance, athleticism, and academic competence? International Journal of Behavioral Development, 33(4), 303-311.

Wasserman, A. L., Thompson, E. I., Wilimas, J. A., \& Fairclough, D. L. (1987). The psychological status of survivors of childhood/adolescent Hodgkin's disease. American Journal of Diseases of Children, 141(6), 626-631. 
Watson, J., \& Nesdale, D. (2012). Rejection sensitivity, social withdrawal, and loneliness in young adults. Journal of Applied Social Psychology, 42(8), 1984-2005.

Woodhouse, S. S., Dykas, M. J., \& Cassidy, J. (2012). Loneliness and peer relations in adolescence. Social Development, 21(2), 273-293.

World Health Organization. (2013). Health topics: Chronic diseases. Retrieved from http:// http://www.who.int/topics/chronic_diseases/en/.

Zakin, D. F. (1983). Physical attractiveness, sociability, athletic ability, and children's preference for their peers. Journal of Psychology, 115(1), 117-122. 
Appendix A

Participation Consent Form

\section{Dear Participant,}

This letter is a request for you to take part in a research project to assess how emerging adults perceive peer acceptance. This project is being conducted by Megan Samples, a graduate student in the Child Development and Family Studies program at WVU with supervision of Dr. Jessica Troilo, an assistant professor in the College of Education and Human Services, for a Master's Degree in Educational Psychology. Your participation in this project is greatly appreciated and will take approximately 10 minutes to fill out the attached questionnaire.

Your involvement in this project will be kept as confidential as legally possible. All data will be reported in the aggregate. You must be 18 years of age or older to participate. Your participation is completely voluntary. You may skip any question that you do not wish to answer, and you may discontinue at any time. Your class standing will not be affected if you decide either not to participate or to withdraw. West Virginia University's Institutional Review Board acknowledgement of this project is on file.

I hope that you will participate in this research project, as it could be beneficial in understanding the influence of peer acceptance among emerging adults. Thank you very much for your time. Should you have any questions about this letter or the research project, please feel free to contact Megan Samples at (304) 293-3424 or by e-mail at mesamples@mix.wvu.edu. Thank you for your time and help with this project.

Sincerely, Megan Samples 
Appendix B

Demographic Questionnaire

Please answer the following questions.

1. What is your age (in years)?

2. I am a: male female (please choose one)

3. Please specify your race:

American Indian / Alaska Native

Asian

Black or African-American

Native Hawaiian or Other Pacific Islander

White

More than one race

Other: Please specify

4. What was the size of your graduating high school class?

5. Who do you know who has or has had cancer?

Myself

Immediate family member

Extended family member

Friend

Acquaintance

None 


\section{Appendix C}

\section{Healthy Male Vignette}

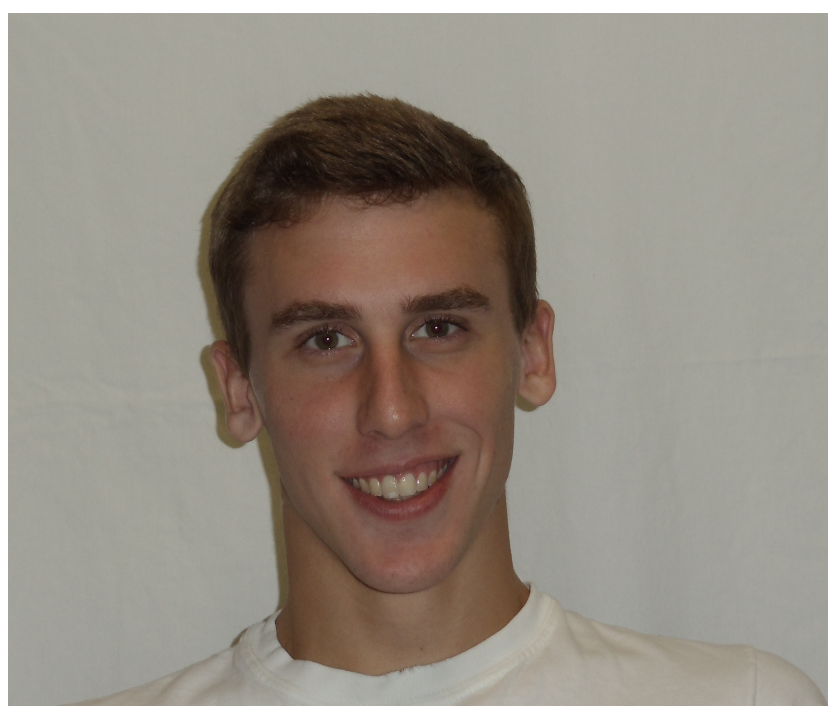

This is a college student at a university similar to West Virginia University. He attended college after he graduated high school when he was 18 . He wasn't sure what to major in when he began college, but has recently decided on what he thinks he wants to do after graduation. Even though he graduated from high school not that long ago, he feels older and different than most adolescents still in high school. Further, even though a lot of people call him an adult, he doesn't quite feel like an adult. He has some anxiety about what he'll do after graduation, but also is excited for what may happen after college. Outside of typical sicknesses (e.g., colds, flus), he has been healthy for most of his life. Rarely has he missed school because of sickness, and he seldom has missed college classes because of illness. 


\section{Appendix D}

Healthy Female Vignette

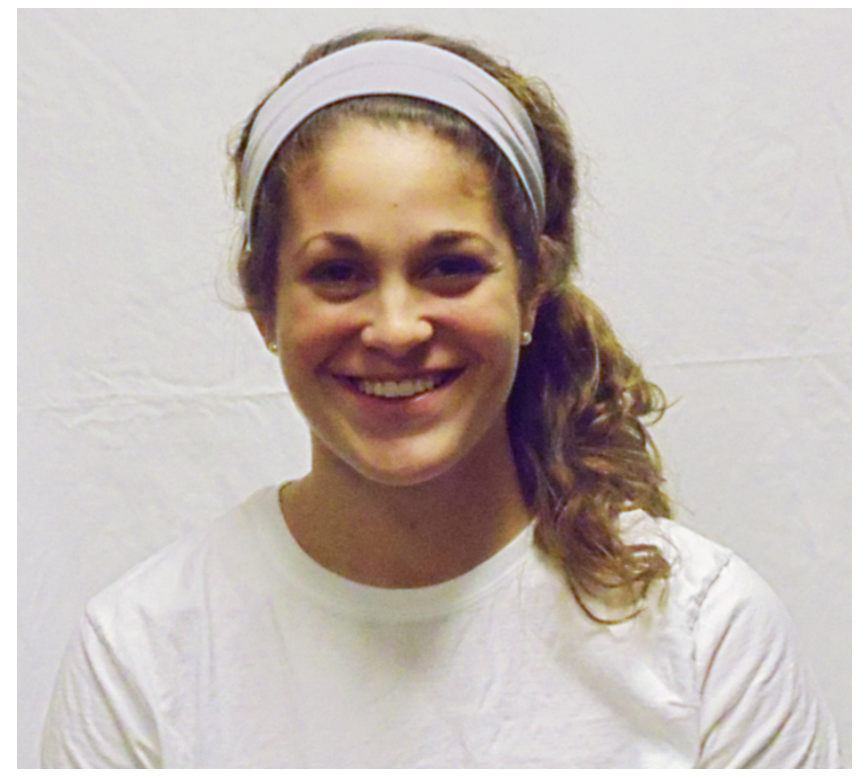

This is a college student at a university similar to West Virginia University. She attended college after she graduated high school when she was 18 . She wasn't sure what to major in when she began college, but has recently decided on what she thinks she wants to do after graduation. Even though she graduated from high school not that long ago, she feels older and different than most adolescents still in high school. Further, even though a lot of people call her an adult, she doesn't quite feel like an adult. She has some anxiety about what she'll do after graduation, but also is excited for what may happen after college. Outside of typical sicknesses (e.g., colds, flus), she has been healthy for most of her life. Rarely has she missed school because of sickness, and she seldom has missed college classes because of illness. 


\section{Appendix E}

\section{Chemotherapy Male Vignette}

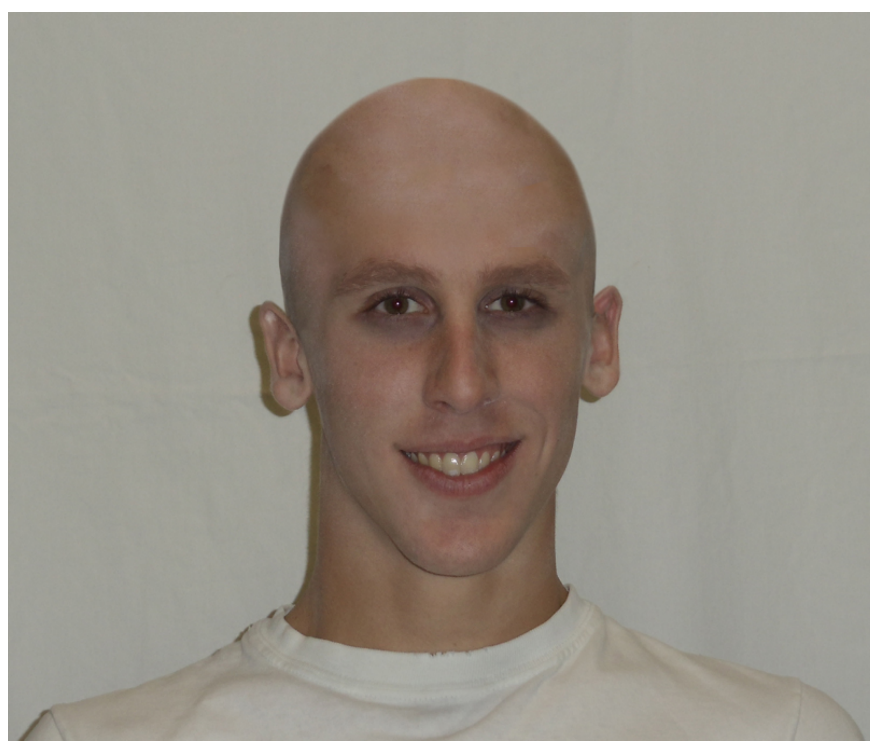

This is a college student at a university similar to West Virginia University. He attended college after he graduated high school when he was 18 . He wasn't sure what to major in when he began college, but has recently decided on what he thinks he wants to do after graduation. Even though he graduated from high school not that long ago, he feels older and different than most adolescents still in high school. Further, even though a lot of people call him an adult, he doesn't quite feel like an adult. He has some anxiety about what he'll do after graduation, but also is excited for what may happen after college. He has been diagnosed with cancer and is currently undergoing treatments, which have caused him to lose his hair. He often feels sick and/or tired, but wants to attend class as often as he can. Unfortunately, because of his treatments and how he feels afterwards, he has missed school often because of sickness. 


\section{Appendix F}

\section{Chemotherapy Female Vignette}

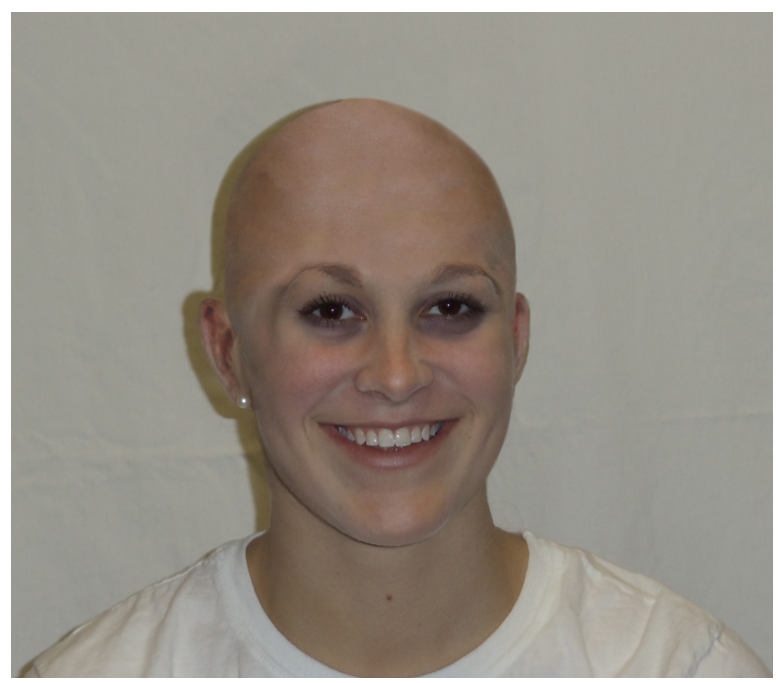

This is a college student at a university similar to West Virginia University. She attended college after she graduated high school when she was 18 . She wasn't sure what to major in when she began college, but has recently decided on what she thinks she wants to do after graduation. Even though she graduated from high school not that long ago, she feels older and different than most adolescents still in high school. Further, even though a lot of people call her an adult, she doesn't quite feel like an adult. She has some anxiety about what she'll do after graduation, but also is excited for what may happen after college. She has been diagnosed with cancer and is currently undergoing treatments, which have caused her to lose her hair. She often feels sick and/or tired, but wants to attend class as often as she can. Unfortunately, because of her treatments and how she feels afterwards, she has missed school often because of sickness. 


\section{Appendix G}

Peer Acceptance Measure

Directions: Using the scale below, please answer the following questions based on the short story you have just read.

After reading the description of the person, please choose the best word that would begin the following statements, using the scale below.

$\begin{array}{lllll}\text { None } & \text { Few } & \text { Some } & \text { Most } & \text { All } \\ 1 & 2 & 3 & 4 & 5\end{array}$

1. __ of this person's classmates want to spend time with this person outside of class if this person asked them.

2. ___ of this person's classmates want to study together for a test after class if this person asked them.

3. __ of this person's classmates want to sit near this person in class.

4. ___ of this person's classmates want to pick this person as a partner in class.

5. ___ of this person's classmates ask this person to spend time with them outside of class.

6. ___ of this person's classmates ask this person to study together for a test after class.

7. ___ of this person's classmates ask this person to hangout with their friends.

8. ___ of this person's classmates ask this person to go to a coffee shop after class.

9. ___ of this person's classmates are comfortable having this person in class.

10. ___ of this person's classmates are comfortable with this person's physical appearance.

11. ___ of this person's classmates ARE NOT embarrassed by being seen with this person outside of class.

12. ___ of this person's classmates ARE NOT embarrassed by how this person looks.

13. of this person's classmates spend time with this person outside of class PRIMARILY because of this person's health status.

14. This person's health is a primary factor for ___ of their classmates when considering spending time with this person outside of class. 
15. This person's health is a primary factor for of their classmates when wanting to spend time with this person outside of class.

\section{Please select yes or no}

16. Do you think that this person has a medical problem?

17. If yes, what do you think the medical diagnosis is? 